\title{
An Analysis of Socio-Cultural Characteristics in Chinese-English Translation of Metaphoric Expressions
}

\author{
Lijun Li \\ School of Foreign Language. North China Electric Power \\ University \\ Beijing, China \\ 1lj0426@163.com \\ Yushan Zhao \\ School of Foreign Language. North China Electric Power \\ University \\ Beijing, China \\ zhaoyushan1963@163.com
}

\author{
Jingjing Xue \\ School of Foreign Language. North China Electric Power \\ University \\ Beijing, China \\ 1543482205@qq.com
}

\begin{abstract}
This paper analyzes metaphoric expressions in Chinese political texts and their English corresponding translations to signify social-cultural characteristics' influence on metaphor translation and how cultural obstacles are overcome in metaphor translation. The analysis proves that in order to overcome cultural barriers in Chinese-English metaphor translation, translators must play their role in bridging cultures of the source text and the target text by employing specific translation methods, such as changing the images, adding "As a Chinese saying goes" to the literal meaning of the metaphor and using descriptive expressions. This paper highlights the importance of sociocultural characteristics in Chinese-English metaphor translation and provide translators with a new train of thought.
\end{abstract}

Keywords-culture; metaphor; Chinese-English translation; true meaning

\section{INTRODUCTION}

Language is an important component and reflection of culture. Anthropologist and linguist Edward Sapir once stated, "Language does not exist apart from culture" [1]. As a process of language transformation and intercultural communication, translation is inevitably influenced by relevant cultures. However, since linguists are the pioneers of the theoretical researches on translation, their early study stayed at the language level [2]. After the transformation of translation theories from language towards intercultural and interdisciplinary researches, cultural factors have been recognized and cultural obstacles are valued in translation. Through the analysis of source texts and target texts, this paper studies the influences of socio-cultural characteristics on Chinese-English metaphor translation and the strategies adopted to overcome cultural barriers. Metaphoric expressions are analyzed from their implied meanings instead of literal meanings. Most metaphoric researches focus on literary texts in which images are more abundant and distinct. In fact, metaphors are also common in formal texts, like political texts. Among political texts, metaphors in political addresses are more frequently affected by culture based on Schäffner's point of view that politicians' addresses are more likely and heavily influenced by the relevant culture than any other political texts [3]. Therefore, this paper analyzes two political addresses of Jinping $\mathrm{Xi}$ to examine how socio-cultural characteristics are reflected and how cultural barriers are dealt with in metaphoric expressions' translation.

Prior to the analysis of the above questions, it is necessary to know about some basic knowledge of metaphor, culture and the relationships among metaphor, culture and translation.

\section{METAPHOR, CULTURE AND TRANSLATION}

Aristotle is the pioneer to conduct the research on metaphor. He defined metaphor as that "Metaphor is the application to one thing of name belonging to another thing" [4]. In previous studies, metaphor is mainly regarded as a rhetorical device. It was after the publication of the book Metaphors We Live By by Lakoff and Johnson, that metaphor started to be considered as a cognitive style. In that book, Lakoff and Johnson [5] defined the essence of metaphor as the understanding and experience of one thing in virtue of another thing. In Newmark's opinion, a metaphor mainly consists of three components including the object, the image and the meaning or the sense [6]. The object is the ontology. The image is the metaphorical object, to which the object is compared. And the sense is the metaphorical meaning which is the connection of the object and the image.

The research values of metaphors are different in accordance with their metaphoric degrees. Metaphors, which are based on people's basic cognition and are shared among different cultures, are less worthy of studying. However, some metaphors, which are created under culture's influence, are active and worthy of research. Metaphors analyzed in this paper are cultural outcomes and socio-cultural characteristics are distinct in them. Although most metaphorical researches focus on literary works for the reason that metaphors in such texts are very vivid, in fact, political texts, which are very 
formal and standardized, also contain many distinct metaphoric expressions. Examples in this kind of text will be provided and analyzed in the following part.

British anthropologist Edward Bernatt Tylor is the first one to define culture. Thereafter, various definitions from different perspectives have arisen. Translation theoretician Nida [7] classified cultural elements into five categories, including ecological culture, material culture, social culture, religious culture and linguistic culture. Besides, according to Cihai, a large-scale Chinese dictionary, the broad sense of culture refers to both material and spiritual wealth created by human beings in the process of human development. Culture is created by human beings based on their practical experiences and it involves many aspects of social lives. Metaphor is also one of its products. Therefore, all these aspects of culture are revealed in metaphors. Kussmaul [8] once mentioned that the distance between the cultures of source text and target text affects the frequency of cultural problems occurring in metaphoric translation. Since Chinese culture is distinctly different from western culture in the aspects of natural condition, social environment, historical tradition, etc., cultural barriers are tough problems in Chinese-English metaphor translations.

The relationship between translation and culture is as close as that between language and culture. Without regard to the influence of culture, translators can neither understand exactly nor translate accurately texts involving cultural factors and it is liable to cause unsuccessful cross-cultural communications. As a product of culture, metaphor is bound to be affected by culture. Therefore, metaphor translations should also be treated with caution in case of the misunderstanding of implied meaning caused by cultural differences. In order to show clearly how socio-cultural characteristics in metaphoric expressions affect Chinese-English metaphor translation and how cultural barriers are overcome, the next part gives specific explanations through several examples.

\section{ANALYSIS OF CHINESE-ENGLISH METAPHOR TRANSLATION}

In this part, examples are selected from President Jinping Xi's keynote speech at the opening plenary of the Boao Forum for Asia Annual Conference in 2013 and his speech at the press conference at the Great Hall of the People as the general secretary of the Central Committee of the Communist Party of China in 2012. And the analysis is mainly made based on the book A Multidimensional and Cross-spherical Study of Cognitive Metaphorology [9].

\section{A. Metaphors Influenced by Literary Tradition and Traditional Value}

During Chinese long history, Chinese litterateurs have created numerous outstanding literary works, in which metaphors are quite common. Many Chinese metaphors have literary origins. The following example is a good case in point.

Source Text (ST): Zai zhong guo wen hua zhong, mei shi er nian shi yi ge sheng xiao xun huan, zhao ci shuo lai, boao ya zhou lun tan zheng chu zai yi ge xin de qi dian shang, xi wang neng geng shang yi ceng lou.
Literal Translation: In the Chinese culture, 12 years form a zodiac cycle. In this sense, the Boao Forum has reached a new starting point and I hope it will go even upstairs.

Target Text (TT): In the Chinese culture, 12 years form a zodiac cycle. In this sense, the Boao Forum has reached a new starting point and I hope it will scale an even greater height.

The Chinese expression "geng shang yi ceng lou” comes from a Tang poem named stepping upon the stork tower. The whole sentence is "yu qiong qian li mu, geng shang yi ceng lou.". This sentence means that if you want to broaden your horizon, you would better go upstairs. Because the higher you climb, the more scenery you will enjoy. Chinese poets prefer to utilize metaphors in poems because of their rich implied meanings. The thoughts and emotions of poets are reposed in those metaphors. In the aforementioned poem, the poet made use of the phenomenon that going upstairs would provide him a wider view to express his opinion that the more you intend to gain, the more you have to contribute. In the speech, Jinping Xi cites the verse to state his hope that the Boao Forum will achieve more and move to a greater height. However, westerners are not familiar with this Chinese poem and they cannot understand the true meaning of the verse. Therefore, the translator must express its implied meaning in target text instead of translating the verse directly into English. So in order to translate it accurately, the translator uses descriptive expression to convey its true meaning.

China and western countries differ in ideology and values. This is due to their different social history and cultural traditions. Under the influence of different ideology and values, metaphors rooted in both cultures also show differences.

\section{ST: “Qin wang qin hao, lin wang lin hao.”}

Literal Translation: Neighbors wish each other well, just as loved ones do to each other.

TT: As a Chinese saying goes, neighbors wish each other well, just as loved ones do to each other.

Chinese people advocate collectivism. In their traditional values, collective interests are always put before personal interests. Hence, the favor of collectivism is reflected in many Chinese proverbs. In the above example, Jinping Xi uses this proverb to show China's willing to strengthen cooperation with its neighboring countries so that they can make common progress and achieve mutual benefits. Relatives and neighbors here are a metaphor for the relationship among China and its surrounding countries. This proverb has a distinctive Chinese characteristic. It is easy to understand the implied meaning just from the proverb's literal meaning according to the above translation. However, since collectivism is not popular and deep-rooted in western countries compared with the situation in China, the translator puts the expression "As a Chinese saying goes" before the sentence to convey this kind of Chinese value. In this way, target readers can have a better understanding of the status of collectivism among Chinese people and know about some cultural knowledge of Chinese.

\section{B. Metaphors Influenced by Customs and Lifestyles}

Different nations have different customs. These customs are cultural heritages, and they are reflections of a given culture. 
Metaphors are inseparable from the customs and are affected by them.

ST: Guo jia wu lun da xiao, qiang ruo, pin fu, dou ying gai zuo he ping de wei hu zhe he cu jin zhe, bu neng zhe bian da tai, na bian chai tai, er ying gai xiang hu bu tai, hao xi lian tai.

Literal Translation: Countries, whether big or small, strong or weak, rich or poor, should all contribute their share to maintaining and enhancing peace. They should repair the stage and offer a succession of excellent show in opera instead of taking down the stage set up by others.

TT: Countries, whether big or small, strong or weak, rich or poor, should all contribute their share to maintaining and enhancing peace. Rather than undercutting others' efforts, countries should complement each other and work for joint progress.

The metaphors in the above sentence are related to Chinese opera. Chinese people are fond of watching Chinese opera in their leisure time. Therefore, they are familiar with the "opera stage” on which operas are shown. In addition, in ancient China many theatrical troupes performed all over the country instead of staying in the same city for a long time and the opera stages were usually built temporarily. It is no doubt that Chinese people know well about the phenomena of dismantling and building opera stages. As a result, there are many metaphoric expressions related to "opera stage”. In the speech, Jinping Xi stresses the importance of maintaining world peace with cooperated efforts. In order to convey this idea visually, he applies a series of stage-related metaphoric expressions to advocate that countries should cooperate with each other to make continuous progress rather than destroy others' efforts. Dismantling the stage means doing harm to others' results, and repairing the stage refers to the cooperation with others. All these phenomena are not so common in western countries than in China. Thus the translator chooses to use descriptive expressions to convey the metaphoric meanings.

As an important part of culture, lifestyle also plays a role in the creation of metaphors. Chinese people have created many metaphors based on their life experiences. The next two examples are relevant to Chinese people's everyday lives.

ST: Shi xian ge guo gong tong fa zhan, yi ran ren zhong er dao yuan.

Literal Translation: Achieving common development for all countries remains a long way with a heavy burden.

TT: Achieving common development for all countries remains an uphill battle.

The underlined words in the ST is selected from The Analects of Confucius, which records Confucius' wisdom and his communications with the students. "ren zhong er dao yuan" means that the road ahead is still very long and the burden on the shoulder is very heavy. This sentence is used as a metaphor to mean that the responsibility on the shoulder is heavy and there is a need for a long-term struggle in order to achieve great success. In ancient times, it was not convenient for Chinese people to go out for a long distance because of the poor transportation and heavy burden. And Chinese people were plagued by it for a long time. Therefore, they use the metaphoric meanings of long road and heavy burden to signify that it is far from success and great efforts are still required. President Jinping Xi applies this expression to indicate the need for long-term striving for the common development of all countries. Western countries are different from China in the selection of the image, which depends on the different environments they live in. They suffered more from uphill battles than from inconvenient traffic. So when they denote the implied meaning mentioned above, they prefer to use the metaphor "uphill battle". Hence, in order to well deliver the true meaning, the translator changes the image for a more common one for the TT.

\section{ST: Da tie hai xu zi shen ying.}

Literal Translation: The blacksmith must be very strong if he want to be excellent in iron forging.

TT: To address these problems, we must first of all conduct ourselves honorably.

This example is a part of a Chinese proverb. "Da tie hai xu zi shen ying, xiu hua yao de shou mian qiao.” is the complete expression of the proverb. In English, "da tie" means to forge iron and "xiu hua" means to embroider. Iron forging was a common occupation in ancient China and embroidering is a Chinese folk handicraft. They are both related to Chinese people's daily lives. The literal meaning of this proverb is that only if the blacksmith is skillful, can he be competent in iron forging and the person who embroiders well must has a pair of dexterous hands. The added meaning of the proverb is that people who advocate something must set themselves an example to others. Before the quotation of the proverb, Jinping $\mathrm{Xi}$ mentions the challenges and problems faced by the party and advocates that the party should make every effort to solve these problems. Therefore, in the following part, Jinping Xi uses this proverb to indicate that in order to solve the problems, party members should at first conduct themselves strictly. Iron forging was a familiar occupation in ancient China, and many Chinese proverbs choose it as a metaphor, for example "strike while the iron is hot". However, this image is not common in western countries. Thus the literal translation of the proverb does not carry the implied meaning as it does in source text. Therefore, the translator paraphrases the proverb and translates it in a descriptive way.

\section{Metaphors Influenced by Religion and Mythology}

Religious stories and myths are also active factors in the creation of metaphors. Metaphoric expressions grown out of religious stories and myths bring about cultural barriers in Chinese-English metaphor translations.

\section{ST: Ya zhou he zuo xu yao bai chi gan tou, geng jin yi bu.}

Literal Translation: the cooperation in China need to move forward for a further step than the head of a more than 30 meters bamboo pole.

TT: We need to build on past success and make new progress in promoting cooperation in Asia.

This example is a metaphor found in a Chinese folktale happened in Song Dynasty. It is said that the eminent monk Zhaoxian was invited to give a sermon in a temple. During the 
sermon, he talked about the highest state of Buddhism with a monk and explained it with a verselet. The general idea of this verselet is that the 30 -meter bamboo pole is not high enough and it is necessary to go further since the highest state is the real destination. The underlined proverb "Bai chi gan tou, geng jin yi bu" is derived from the verselet. Its metaphoric meaning is that even if you have made some achievements, you still need to work hard so that you can achieve more. In the ST, Jinping $\mathrm{Xi}$ quotes this proverb to indicate that new and great progress should be made for the promotion of Asian countries' cooperation. When the translator translates this sentence, he encounters some difficulties because of the cultural differences. Buddhism is prevailing in China. Thus folktales related to it are numerous. However, the situation is different in western where Christianity is the mainstream. Besides, the images are also unfamiliar with westerners. Therefore, the translator translates the proverb into a descriptive expression.

ST: Dang ling dao ren min yi jing qu de le ju shi zhu mu de cheng jiu, wo men wan quan you li you yin ci er zi hao, dan wo men zi hao er bu zi man, jue bu hui tang zai guo qu de gong lao bu shang.

Literal Translation: It has led the people in making worldrenowned achievements, and we have every reason to take pride in these achievements. But we are not complacent, and we will never rest on the booklet which is used to record our feats.

TT: It has led the people in making world-renowned achievements, and we have every reason to take pride in these achievements. But we are not complacent, and we will never rest on our laurels.

In Chinese mythologies, immortals have many booklets. They use these booklets to record different things. It is said that the booklet, in which birth date, death time and lifespan of all creatures are recorded, is named "sheng si bu". "gong lao bu" is similar to "sheng si bu", but it records creatures' feats instead. Afterwards, the expression "gong lao bu" is used to refer to past achievements. Jinping Xi applies this metaphor to signify that party members should make new contributions rather than live on their past achievements. Since "gong lao bu" is a product of Chinese mythology, it is likely to create cultural barriers. In order to overcome this problem, the translator introduces a new image "laurel". "Laurel" is an outcome of the Greek mythology. The myth is a love story in regard to Apollo, son of Zeus and Daphne, daughter of Peneus. Apollo falls in love with Daphne and starts to pursue her. However, Daphne rejects him and changes herself into a laurel with her father's help. Even so, Apollo is still crazy about her and treats laurel with respect. He bestows Laurels to the outstanding persons. Afterwards, "laurels" are used to show honor and feats. The application of this metaphor in TT makes it easier for target readers to understand the sentence. In this example, the image is changed.

Socio-cultural characteristics have great effects on ChineseEnglish metaphor translation. These characteristics, including literary tradition, traditional value, customs, etc., form cultural obstacles in translations. In order to overcome these obstacles, the translator adopts different translation methods. These methods are as follows: firstly, changing the image to a familiar one; secondly, adding "As a Chinese saying goes” to show Chinese characteristics; thirdly, applying descriptive expressions. The application of these methods avoids the distortion of metaphoric meanings and is conductive to crosscultural communications.

\section{CONCLUSION}

This paper introduces some basic knowledge of metaphor and culture and summarizes the relationship among metaphor, culture and translation. Besides, the paper studies the translation of metaphoric expressions in political addresses and analyzes some socio-cultural characteristics, which influence the Chinese-English translation of metaphors. Those cultural factors are literary tradition, traditional value, customs, lifestyles, religion and mythology. In addition, some strategies used to overcome cultural barriers have been summarized. Those methods include the replacement of the images, the addition of "As a Chinese saying goes" to the literal meaning and the employment of descriptive expressions.

It is obvious that cultural factors are insurmountable obstacles in Chinese-English metaphor translation. Metaphor translation calls for sufficient cultural knowledge. Thus, translators responsible for metaphor translation should pay more attention to cultural barriers. If cultural factors are ignored in metaphor translation, implied meanings of metaphors are likely to be distorted and obstacles will occur in cross-cultural communications. And only when cultural factors are recognized, can translators choose appropriate translation method for each metaphor so that the true meaning can be well delivered from the ST to the TT and provide target readers with the same reading experiences as source readers. This paper puts forward a referential perspective for Chinese-English metaphor translation.

\section{ACKNOWLEDGMENTS}

This research was supported by "The Fundamental Research Funds for the Central Universities” in 2013 named as "Cognitive practice research on the application of metaphor and image schemas in lexical polysemy" (No. 13MS51) and "The Fundamental Research Funds for the Central Universities" in 2014 named as "Research on Western postmodernism and Translation” (No. 2014 ZD25).

\section{REFERENCES}

[1] E. Sapir, Language: An Introduction to the Study of Speech. New York: Harcourt, Brace, 1921.

[2] Jun Xu, On Translation. Beijing: Foreign Language Teaching and Research Press, 2009.

[3] C. Schäffner, "Strategies of translating political texts," In Text Typology and Translation, A. Trosborg, Ed. Amsterdam and Philadelphia: Benjamins, 1997.

[4] Aristotle, Rhetoric and Poetic. New York: The Modern Library, 1954.E.

[5] G. Lakoff and M. Johnson, Metaphors We Live By. Chicago: University of Chicago Press, 1980.

[6] P. Newmark, A Textbook of Translation. Shanghai:Shanghai Foreign Language Education Press, 2001.

[7] A. Nida, Towards a Science of Translating. Leiden: Brill, 1964.

[8] P. Kussmaul, Training the Translator. American and Philadelphia: John Benjamins, 1995.

[9] Yi Sun, A Multidimensional and Cross-spherical Study of Cognitive Metaphorology. Beijing: Peking University Press, 2013. 